\title{
Análise comparativa da microconstrução um belo dia / un bel giorno no português brasileiro e no italiano
}

\author{
Comparative analysis of the micro-construction um belo dia / un bel \\ giorno in Brazilian portuguese and Italian
}

\author{
Vânia Cristina Casseb Galvão ${ }^{1}$ \\ Carlotta Boellis ${ }^{2}$
}

\begin{abstract}
Resumo: Toda língua apresenta expressões idiomáticas em seu repertório escrito e oral. Essas expressões às vezes vêm de contextos completamente diferentes daqueles utilizados hoje em dia, de modo que nos perguntamos como elas chegaram às suas formas atuais, quais foram suas evoluções linguísticas e se a sociedade e as vicissitudes históricas tiveram um impacto em sua transformação. É o caso das microconstruções equivalentes um belo dia no português brasileiro e un bel giorno em italiano. Sendo assim, este artigo parte da analise pancrônica promovida por Silva (2017) e da sua descrição dos usos dessa microconstrução no português brasileiro segundo os contextos de Diewald (2002), em particular. O artigo compreende uma parte teórica inicial, baseada em princípios do Funcionalismo e da Gramática das Construções; uma segunda parte voltada para a análise de dados derivados de corpus do italiano histórico, na qual se faz uma contextualização sócio-histórica, e, em seguida, a análise dos contextos de uso dessas microconstruções no italiano.
\end{abstract}

Palavras-chave: Um belo dia. Un bel giorno. Microconstrução. Gramática de Construções. Diacronia.

\begin{abstract}
Each language contains idioms in its written and oral repertoire. These expressions sometimes come from contexts completely different from those used today, so we ask how they got to their current forms, what their linguistic evolutions were, and whether society and historical vicissitudes had an impact on their transformation. This is the case of the twin micro-constructions um belo dia in Brazilian Portuguese and un bel giorno in Italian. This article starts from the panchronic analysis of Silva (2017) and its description of the uses of the micro-construction in Brazilian Portuguese according to the contexts of Diewald (2002), in particular. The article includes an initial theoretical part, based on the subjects of Functionalism and Constructional Grammar, a second part of analysis of data derived from the Italian historical corpus, with socio-historical contextualization and a part of analysis of the contexts of use of the Italian micro-constructions.
\end{abstract}

Keywords: Um belo dia. Un bel giorno. Micro-construction. Construction Grammar. Diachrony.

\footnotetext{
${ }^{1}$ Universidade Federal de Goiás, Faculdade de Letras, Departamento de Estudos Linguísticos e Literários, Goiânia, GO, Brasil. Endereço eletrônico: vaniacassebgalvao@ gmail.com.

${ }^{2}$ Università del Salento, Lecce, LE, Itália. Endereço eletrônico: carlotta.boellis@ gmail.com.
} 


\section{Introdução}

Este artigo apresenta os resultados da análise dos usos e da mudança envolvendo a microconstrução italiana un bel giorno, a partir da comparação com a sua equivalente no português brasileiro (PB) um belo dia, considerando a análise descritivo-construcional de Silva (2017), e de Silva; Casseb-Galvão (2018, 2019), conforme resumido a seguir:

Silva (2017) faz uma exaustiva descrição dos usos da microconstrução um belo dia no $\mathrm{PB}$, tendo como justificativa a polissemia desse pareamento, conforme (1) e (2), a seguir:

(1) [...] Mestre Cosme armara-lhe uma rede no alpendre e fora-se a desbastar a mata, escanchado na Coruja. Fazia um belo dia de sol, calmo e luminoso. O arvoredo imóvel dormitava na esplêndida pulverização da luz que o narcotizava para beber-lhe a seiva. $\mathrm{O}$ passaredo aninhava-se na verde espessura dos cajueiros em flor, contubernal e gárrulo; rolas bravas debicavam nas clareiras os minúsculos diamantes que o sol punha na areia. (A normalista, Adolfo Caminha, Corpus do Português).

(2) [...] Este, um temperamental, um belo dia cansou de tantos estudos, cálculos, tabelas, orçamentos, índices contraditórios, estatísticas expurgadas e planos mirabolantes, ainda mais quando se aproximavam eleições para o Congresso e o seu serviço de informações o advertira da crescente impopularidade do governo: convocou uma reunião ministerial, exigindo a presença de todos os titulares [...] (A greve dos desempregados, Luiz Beltrão, Corpus do português)

Um belo dia exerce funções sintáticas e semânticas diferentes nas duas instanciações, pois em (1), ele integra a estrutura oracional básica, tem uma estruturação composicional, preenche a casa do único argumento de verbo apresentacional, constitui um sintagma adjetival, tem significação mais concreta, voltada para o tempo físico e atua em uma sequência textual descritiva. Já em (2), um belo dia é um todo significativo mais abstrato, um opreador que atua no nível da organização do texto, e é auxiliar na organização da estrutura narrativa e do seu climax.

Em uma abordagem pancrônica, Silva (2017) analisou esse pareamento no lapso entre os séculos XIX, XX e XXI. A autora distinguiu todos os usos de um belo dia, os descreveu segundo o modelo de Croft (2001), atentando para as suas propriedades sintática, morfológica, fonológica, semântica, pragmática e discurso-funcional; conforme proposto por Diewald (2002), analisou seus contextos de gramaticalização; e, seguindo a teoria construcional de Traugott; Trousdale (2013), os analisou também considerando as dimensões tamanho, especificidade e conceito, e os fatores hierárquicos esquematicidade, composicionalidade e produtividade.

Mais especificamente quanto aos contextos de gramaticalização, Silva (2017) 
distinguiu três estágios: contexto típico (de valor lexical), atípico (polissêmico, ambíguo) e crítico (valor gramatical), e analisou os seus usos representativos, considerando a posição na frase, a sequência textual que integram e a sua função na organização do texto. Ela chegou à seguinte conclusão:

No contexto típico, o pareamento um belo dia pode ocorrer anteposto e posposto ao verbo, uma prerrogativa de sua formação composicional, e tanto em uma sequência descritiva quanto narrativa. O contexto atípico apresenta a microconstrução também anteposta e posposta ao verbo, predominantemente, em uma sequência narrativa, em um adjunto adverbial. No contexto crítico, aparece mais anteposta ao verbo, predominantemente, encabeçando uma sequência narrativa, funcionando como um operador textual. (SILVA, 2017, p. 122)

Para melhor revelar a mudança ocorrida no pareamento, Silva (2017, p. 124) compara os extremos do continuo de mudança, cujos polos mais concreto e mais abstrato são os usos do contexto típico e crítico:

\section{Um belo dia concreto}

Atuação primária: oração básica

\section{Função primária}

Organização do predicado

Argumental, informação na descrição espaço- temporal

\section{Função secundária}

Integra sequências descritivas em texto narrativo.

\author{
Um belo dia abstrato \\ Atuação primária: nível textual \\ Função primária \\ Organização interoracional, textual \\ Integra e organiza sequências \\ narrativa
}

Silva (2017) afirma que um belo dia em contexto crítico perde propriedades composicionais (em relação ao contexto típico) e integra a rede dos operadores textuais introdutores de clímax da narrativa, como de repente, quando dei fé, quando dei por mim.

Feito esse breve resumo do trabalho que fornecerá a contraparte da análise comparativa, podemos dizer que pretendemos, em particular, descrever os usos do pareamento un bel giorno em italiano, conhecer a sua evolução, durante o mesmo período analisado por Silva (2017) e Silva; Casseb-Galvão (2018, 2019), distinguir sua funcionalidade e estruturação, tendo como parâmetro o que se verificou para o par equivalente em português e a teoria de contextos de gramaticalização proposta por Diewald (2002). Isso porque, também como verificado em português, no caso de un bel giorno, distinguimos, em uma 
análise preliminar do italiano contemporâneo, pelo menos, duas diferentes funções desse conjunto: uma descritiva, para indicar que o dia está lindo, agradável, ensolarado; e uma segunda, textual-narrativa, introdutora do clímax da narrativa ou indicadora de uma mudança não esperada no curso dos acontecimentos. Em seu trabalho, Silva (2017) traz uma descrição exaustiva a partir de vários princípios teóricos da Linguística Funcional Centrada no uso (LFCU) e da Gramática de Construções (GrxConstr), mas, por delimitação editorial, restringiremos nossa análise aos objetivos anteriormente elencados.

Sendo assim, este artigo está dividido em três partes. Na primeira parte serão apresentados os princípios teóricos que fundamentam a pesquisa, em particular, as noções de construção e microconstrução (GOLDBERG, 1995; MASSINI, 2016), e a noção de contextos de gramaticalização (DIEWALD, 2002). Na segunda parte do artigo, serão apresentados os corpora que ofereceram os dados relevantes para a pesquisa e o resultado quantitativo inicial. Em seguida, faremos uma análise sócio-histórica dos usos verificados e promovemos uma análise dos seus contextos evolutivos: típico, atípico e crítico. Será também analisada a organização do paradigma italiano, diferenciais e pontos em comum entre este e a contraparte brasileira. A frequência de usos representativos desses contextos foi analisada a partir do contexto sócio-histórico-político da sociedade italiana no período compreendido entre os séculos XIX e XXI.

As conclusões reúnem as especificidades do pareamento italiano frente à sua contraparte brasileira, em uma opção de resposta à seguinte pergunta geral de pesquisa: quanto à sua estruturação, uso, frequência e funcionalidade, as microconstruções derivadas do pareamento un bel giorno revelam um percurso de mudança equivalente ao de sua "alma gêmea" (expressão equivalente) um belo dia, em português, conforme descrito por Silva (2017)?

\section{Base Teórica}

Para melhor analisar a microconstrução um bel giorno, sua formação, frequência, funcionalidade e uso temos que, assim como Silva (2017), considerar como base teórica os assuntos do Funcionalismo, especialmente da Linguística Funcional Centrada no Uso (LFCU) e da Gramática de Construções (GRCx). A escolha pela LFCU se dá porque a riqueza da diversidade linguística é melhor compreendida se estudada a partir da situação comunicativa, da sua natureza e fluidez. E a opção pela GRCx permite uma visão dessa microconstrução como parte de uma rede, o próprio sistema linguístico, cujas partes componentes são interconectadas e interdependentes, e, portanto, permite analisar a sua interrelação com outras 
entidades linguísticas funcionalmente correlatas. Adotar uma visão funcionalista é mesmo importante, pois permite considerar igualmente a forma (aspectos morfossintáticos, fonológicos e prosódicos) e a função (aspectos semânticos, pragmáticos, discursivos e funcionais) de uma construção.

A partir de Fillmore (1988) e de Goldberg (2006), uma construção é definida como um pareamento de forma e significado que, ademais, não pode ser entendido a partir da análise das suas partes individuais. Ela é reconhecida a partir desse conjunto estrutural e formal significativo. As construções, no entanto, não aparecem de repente na língua. Em primeiro lugar, elas derivam dos construtos, ou seja, das realizações linguísticas concretas produzidas pelos falantes, que são responsáveis pela evolução da linguagem.

As microconstruções constituem relações hierárquicas: de fato, se elas são partes de uma rede, integram então um subesquema, que deriva de um esquema mais geral. $\mathrm{O}$ fato de integrarem subesquemas, não significa que as (micro)construções são fixas e imóveis. Ao invés, isso significa que as ligações no âmbito da rede construcional as influenciam, pondo em marcha processos de mudança. Como afirma Justino (2018, p.49), "a mudança é o resultado de inovações no uso e realinhamento de aspectos funcionais e/ou formais das unidades da língua dentro da rede conceptual”. O processo de mudança não é abrupto, mas ocorre através de alguns micropassos (TRAUGOTT; TROUSDALE, 2013), dos quais citamos inovação, neoanálise, analogização, convencionalização e construcionalização.

Não nos deteremos a definir cada um desses micropassos, que são amplamente conhecidos na área dos estudos construcionais, mas cabe dizer que é possível traçar uma trajetória da mudança, reconhecendo que a construção se organiza em níveis a partir de um padrão mais geral, abstrato (do esquema), que pode derivar níveis intermediários (subesquemas), aos quais estão atreladas microconstruções (esquemas-type); os construtos, por sua vez, são tokens instanciados na situação comunicativa particular, podem ser falados ou escritos e ajudam a moldar a representação mental da linguagem (TRAUGOTT; TROUSDALE, 2013).

Assim, quando consideramos as construções como pareamento de forma e função

[...] os contextos internos correspondem às influências no entorno da forma linguística, ao passo que os contextos externos correspondem aos aspectos funcionais que influenciam na constituição da construção, desde as influências cognitivas às discursivo-pragmáticas." (JUSTINO, 2018, p. 54) 
De toda maneira, podemos mencionar quanto às influências externas, o uso pelo falante em situações interativas diversas e em diferentes domínios sócio-históricos e políticos, a adoção da construção em ambiente estrutural diverso do típico, eventuais inadequações de uso etc. Estas têm um valor enorme na mudança que afeta as construções de qualquer tipologia.

Para melhor compreender como sucede a mudança e quais fatores estão a ela relacionados, uma opção que entendemos interessante envolve a adoção de um ponto de vista diacrônico, pois na maioria dos casos o estudo ao longo do tempo facilita a percepção das evoluções linguísticas. Por isso, como Silva (2017), recorremos à contribuição de Diewald (2002) quanto à uma abordagem diacrônica da mudança linguística e aos micropassos (internos) que levam à construcionalização de un bel giorno (mudança em ambas as faces do pareamento):

1) Contexto típico: a (micro)construção está na sua forma básica, original, mais lexical.

2) Contexto atípico: primeiro estágio do processo de gramaticalização. A construção se destaca do seu uso original e pode ser registrada em contextos diferentes e a partir de usos inovadores. Acontecem novas influências pragmáticas e semânticas.

3) Contexto crítico: é ativado o processo de gramaticalização. A construção ainda está relacionada a diferentes usos e significados, que originam interpretações diferentes.

4) Isolamento: a gramaticalização é instaurada. Coexistem as duas construções: a primeira com seu significado original e lexical, e a segunda, mais recente e gramatical. Nesta fase é certo dizer que as duas têm usos e contextos diferentes não susceptíveis de confusão.

Resulta central o conceito de gramaticalização, e, para relembrar sua definição, uma vez que é um fenômeno muito estudado até então, é necessário partir da noção de processo, uma vez que a linguagem nunca é um estado ou um produto, mas um fazer-se e refazer-se, uma atividade contínua e, como tal, instável por definição. E, se considerarmos a linguagem como em constante mudança, não deveríamos considerar também o tempo ao longo do qual ela muda? A partir daí, podemos dizer também que a noção de gramaticalização permite superar a lacuna entre análises voltadas para a sincronia ou para a diacronia, ou seja, esse tipo especial de mudança pode ser percebido sincrônica ou diacronicamente, mas é essencialmente um processo diacrônico, ou seja, diz respeito à mudança linguística no tempo e, neste caso, ao nascimento de novas estruturas (construções, microconstruções) gramaticais ou mais gramaticais da língua a partir de unidades lexicais ou menos gramaticais. 
A gramaticalização é um processo gradual, de percepção unidirecional, através do qual as unidades lexicais transitam para novos valores gramaticais, perdendo progressivamente autonomia semântica, categorial e, às vezes, fonética. Nesse contexto, não nos interessa tanto verificar a perda de propriedades inerentes à microconstrução origem, mas a aquisição de novas propriedades e funções, especialmente no nível pragmático, ou seja, a extensão do contexto de uso. Pretendemos, portanto, compreender como a microconstrução un bel giorno mudou e quais são os seus contextos de mudança.

\section{Considerações metodológicas}

O objetivo desta seção é apresentar a construção italiana un bel giorno e indicar como os dados foram coletados, selecionados e analisados a partir do corpus de referência, no nosso caso, o corpus do italiano escrito Paisà, disponível em https://www.corpusitaliano.it/.

Esse corpus integra um projeto da Università Di Bologna, compreende fontes extraídas da web e é constituído por 250 milhões de palavras. Esse foi o primeiro corpus de análise, mas necessitávamos de um corpus dividido por períodos históricos, a fim de satisfazer o aspecto diacrônico desta pesquisa. Foi assim que, buscando na internet, encontramos o site do DiaCORIS, um corpus do italiano escrito que compreende estratos de textos escritos em italiano no período entre 1861 e 2001. Utilizar este corpus foi importante por oferecer dados mais precisos a respeito da implementação do processo de mudança ao longo do tempo.

Contrariamente à pesquisa da Silva (2017), que fez uma ampla investigação de natureza pancrônica, nossa pesquisa apresenta fontes e instrumentos bem mais limitados e vai intentar delinear a trajetória da microconstrução un bel giorno, restringindo a análise dos dados disponíveis a uma reflexão de tipo histórico-funcional.

Fizemos uma busca geral no DiaCORIS, a fim de verificar se esse pareamento é usado ao longo do tempo, sem, no entanto, distinguir usos e funções. O número de ocorrências de un bel giorno no tempo considerado é apresentado na tabela a seguir:

Tabela 1: Número de ocorrências por período histórico

\begin{tabular}{|l|l|}
\hline Período histórico & Ocorrências / Percentual \\
\hline $1861-1900$ & $51 / 39 \%$ \\
\hline $1901-1922$ & $20 / 15 \%$ \\
\hline $1923-1945$ & $17 / 13 \%$ \\
\hline $1946-1967$ & $31 / 24 \%$ \\
\hline $1968-2001$ & $9 / 7 \%$ \\
\hline Total & $\mathbf{1 2 8} / \mathbf{1 0 0 \%}$ \\
\hline
\end{tabular}

Fonte: elaboração própria. 
Queremos destacar que, devido às grandes transformações sócio-políticas vividas pela Itália, e toda a Europa, em decorrência das duas guerras mundiais, acontecimentos que mudaram o modo de ver e conceber o mundo dos falantes de italiano, o que certamente influenciou na formação de novos usos da língua, decidimos dividir o século $\mathrm{XX}$ em três períodos, considerando tanto as guerras em si quanto os períodos entreguerra e pós-guerra, a era da reconstrução. Nesse contexto histórico, também se atenta para a processo de formação do Estado italiano aos moldes atuais. Essa divisão se diferencia daquela de Silva (2017), que seguiu rigorosamente a distinção em séculos.

A partir dessas ocorrências, operamos uma diferenciação histórica dos contextos de gramaticalização, segundo a diferenciação de Diewald (2002). O resultado é apresentado na tabela 2 a seguir:

Tabela 2: Contextos de un bel giorno por período histórico

\begin{tabular}{|l|l|l|l|l|}
\hline PERIODO & \multicolumn{1}{|c|}{ Típico } & \multicolumn{1}{c|}{ Atípico } & \multicolumn{1}{c|}{ Crítico } & \multicolumn{1}{c|}{ Total } \\
\hline $1861-1900$ & $1 / 1,8 \%$ & $18 / 35,9 \%$ & $32 / 62,7$ & $51 / 39,8 \%$ \\
\hline $1901-1922$ & $1 / 5 \%$ & $6 / 30 \%$ & $13 / 65 \%$ & $20 / 15,6 \%$ \\
\hline $1923-1945$ & $0 / 0 \%$ & $6 / 35,3 \%$ & $11 / 64,7 \%$ & $17 / 13,3 \%$ \\
\hline $1946-1967$ & $1 / 3,3 \%$ & $14 / 45 \%$ & $16 / 51,7$ & $31 / 24,3 \%$ \\
\hline $1968-2001$ & $0 / 0 \%$ & $5 / 55 \%$ & $4 / 45 \%$ & $9 / 7 \%$ \\
\hline Total & $\mathbf{3 / 2 , 3 \%}$ & $\mathbf{4 9 / 3 8 , 3 \%}$ & $\mathbf{7 6 / 5 9 , 4 \%}$ & $\mathbf{1 2 8} / \mathbf{1 0 0 \%}$ \\
\hline
\end{tabular}

Fonte: elaboração própria.

Os dados descritos na tabela 2 revelam, primeiramente, que a microconstrução gramaticalizada un bel giorno já era amplamente usada no século XIX e oscila em termos percentuais entre o século XIX e o século XX, mas é o uso preferencial em todo o período analisado. Até o ano de 1945, o uso diminui gradualmente, e há novamente uma alta de uso no período 1946-1967. No período mais recente, que vai até 2001, o uso resulta muito limitado na literatura.

Como são temas recorrentes na literatura linguística socio-discursiva, não nos deteremos em longas discussões ou em polemizar as noções de gênero e de tipo ou sequências textuais, por exemplo, mas cabe definir essas duas dimensões da configuração discursivotextual, nível de organização linguística no qual atuam os usos mais abstratizados de um belo dia / um bel giorno. Para a análise, é importante, portanto, consideramos, seguindo Paredes Silva (1997, 2010), que o gênero (discursivo ou textual) identifica uma unidade interacional, caracteriza um modo de condução discursiva vinculado a uma determinada situação comunicativa. Nesta definição estão previstos fatores de ordem externa (ideológicos, sociolinguísticos, psicológicos etc) e interna à organização linguística (funcionais e formais). 
Já os tipos textuais ou sequências textuais são enunciados especialmente distintos na sequenciação textual e analisáveis em seus aspectos formais.

Os tipos textuais são estruturas disponíveis, cuja organização predicativa segue determinadas especificações, são ancoradas nos sistemas de tempo/aspecto/modo do verbo e na dêixis, a partir da centralidade em determinada pessoa do discurso (1a, 2a, e 3a). Paredes Silva (2010) destaca também como parâmetros de distinção dos tipos textuais a tendência pela organização semântica a partir de predicados de natureza mais verbal ou nominal, o predomínio da ordenação lógica ou cronológica, etc. Alguns desses tipos são o narrativo, o descritivo, o argumentativo, o expositivo, injuntivo etc. A autora destaca, por exemplo, entre os aspectos estruturais dos tipos narrativos, a preferência pelo verbo no pretérito perfeito do indicativo, os predicados com verbos de ação, a organização dos eventos em torno da primeira ou terceira pessoa, e a marcada articulação oracional de base temporal.

\section{Analise do processo de gramaticalização}

\section{Correlações sócio-históricas}

Uma hipótese sócio-histórica poderia ser avençada, observando-se a flutuação das ocorrências detectadas nos vários períodos em confronto com o contexto sócio-político de formação da sociedade italiana: o primeiro período é historicamente o do Regno d'Italia, caracterizado por ser uma fase de otimismo geral, de inovação e de construção do Estado. Portanto, se o período é marcado por novidade, poderíamos dizer que un bel giorno (em seu uso crítico) funciona como um incipit, na comunicação linguística, para indicar uma novidade inesperada. Isso é evidente, já naquele período, na preferência por esse contexto que, como se nota, sublinha aspectos novos e inesperados no texto. É preciso salientar que quase a metade das ocorrências deste período pertencem ao romance I Viceré, de Federico de Roberto (1894), um dos livros símbolo do Ressurgimento italiano.

Os dois períodos seguintes (1901-1922 e 1923-1945) são os das duas Guerras Mundiais. Portanto, são períodos de forte pessimismo. Un bel giorno em seu uso crítico pode introduzir algo que vem de repente, é um operador textual, mas não tem o mesmo significado do primeiro período: os usos verificados apresentaram essencialmente conotação negativa, refletindo a situação de guerra e totalitarismo. Observamos uma diminuição das ocorrências de todos os usos da microconstrução (17, 20 unidades totais), e, ao mesmo tempo, o uso de contexto critico é favorito e não foram verificadas ocorrências do contexto típico. Por volta do período 1923-45 registramos novamente um número significativo (6) de ocorrências em 
outras obras símbolo da literatura italiana, no caso, de um par de obras de Italo Svevo, cujas temáticas são desenvolvidas com forte componente psicológico.

Em geral, nesse período os usos da microconstrução de contexto atípico e critico são muito recorrentes no discurso político, por exemplo, em artigos jornalísticos e ensaios, o que pode estar relacionado com uma hipótese de evolução desses usos para contextos menos oficiais ou menos formais. Isso também é evidente, no período 1901-22, em duas ocorrências em romanaccio, o dialeto de Roma e arredores, sinal de que a microconstrução em contexto atípico e critico é presente na linguagem do povo ou, em geral, na linguagem mais vulgar.

O quarto período (1946-1967) diz respeito ao segundo pós-guerra, neste caso, um período de reconstrução. As expectativas, as esperanças e o otimismo renascem, até o ano de 1968, quando ocorrem grandes protestos que representam a concretização de um desejo de mudança sócio-política geral. Com o voltar das esperanças e o otimismo, ainda no quarto período, aumentam as ocorrências de un bel giorno (nos seus contextos atípico e crítico) no âmbito dos jornais impressos (13 ocorrências), que, na época, eram o principal e o favorito veículo de informação da sociedade italiana. Aparecem também em textos narrativos (13 ocorrências), o tipo textual de preferência e mais produtivo para o uso mais inovador dessa microconstrução. Assinalamos uma ocorrência particular desse período:

(3) Ma perché insisti? Se rimani qui tra noi, un bel giorno la identificherai anche tu, la parola proibita, all'improvviso, quasi senza accorgertene. Così è, figliolo mio.

(La Parola Proibita, Sessanta Racconti, Dino Buzzati, 1958, corpus DiaCoris)

(Mas por que você insiste? Se você ficar aqui entre nós, um belo dia você também vai identificá-la, a palavra proibida, de repente, quase sem perceber. É assim que é, meu filho - tradução nossa)

O exemplo em questão resulta interessante pela coocorrência da microconstrução un bel giorno e da locução adverbial all'improvviso (de repente, em português) que, como já mencionamos, representa o significado que a microconstrução adquire no contexto crítico. Poderíamos considerar essa ocorrência de um uso parcialmente atípico e parcialmente crítico, uma vez que o clímax da narrativa não é identificado de imediato e un bel giorno poderia ser considerado equivalente a um dia qualquer. No entanto, o trecho identificherai anche tu, la parola proibita é, certamente, a parte principal da narrativa. Não chega a ser um clímax típico porque seu entorno não é organizado de modo a fazer o texto progredir também do ponto de vista das expectativas do leitor em relação ao desfecho de um evento acontecido, pois está em discurso direto e tem um caráter mais injuntivo, de conselho. A coocorrência de all'improvviso ajuda na construção da ideia de um resultado que chegará de repente, quase 
inesperado, tratando-se, no entanto, de um comentário com projeção futura e não uma narrativa prototípica de fatos passados em um mundo real ou ficcional. No caso, trata-se da representação de eventos do mundo comentado, das ideias.

O último período do corpus histórico é aquele de 1968-2001, no qual registramos dados de confirmação, pois ocorre o aumento do uso mais gramaticalizado em textos jornalísticos e uma ligeira diminuição dos contextos de uso críticos a favor daquele atípico. É evidente, também, uma diminuição gradual das ocorrências totais, se comparadas com o século anterior. É claro, no entanto, que os usos da microconstrução em textos escritos formais diminuem ao longo do tempo, sejam eles de contexto típico ou até crítico. Uma hipótese para explicar isso envolve a preferência por all'improvviso ou por una bella giornata, esta que é a expressão mais frequente em italiano para indicar o percurso temporal e para instanciar o cumprimento mais usado em referência ao longo do dia.

A diminuição drástica do número de ocorrências no século XXI nos levou a um retorno ao corpus Paisà, no qual verificamos 131 ocorrências entre os usos atípico e crítico. A grande maioria desses usos de Un bel giorno ocorreu em interações informais no ambiente da internet, e ultrapassa de largo o número de ocorrências verificadas nos textos de literatura ou jornalísticos mais recentes (1968-2001), do corpus DiaCORIS. Enfim, no italiano, a microconstrução é quase sempre usada em contextos discursivos de menos controle, típico de comentários na Internet. No corpus em questão, referimo-nos a comentários, artigos e, em geral, fontes online nas quais os usuários, embora escrevendo, adotam uma linguagem menos controlada, às vezes, muito próxima à fala.

Apresentados os resultados da análise sócio-histórica e política, cabe apresentar os resultados da análise diacrônica, a partir da proposta a respeito dos contextos de gramaticalização de Diewald (2002) e que retomam a pesquisa de Silva (2017), base para este estudo comparativo.

\section{Análise individualizada dos contextos}

Tal como Silva (2017) verificou para o PB, nossa análise revelou que un bel giorno em contexto típico pertence ao subesquema formal [Artigo indefinido, - específico + Adjetivo + Substantivo], e na medida em que se gramaticalizam, o grau de composicionalidade das microconstruções na forma un bel giorno é diminuído. O contexto crítico funciona como um operador textual, as partes componentes são indecomponíveis e o seu significado é depreendido desse conjunto estrutural. Houve neoanálise no plano sintagmático. A construção original passou por um processo de adaptação e mudança semântica e, ao longo do tempo, os 
falantes atribuem-lhe novos sentidos. Portanto, há um novo nó na rede dos operadores textuais, como all'improvviso, a partir da adaptação e da implementação desses usos inovadores.

Essa evolução pode ser descrita, considerando-se a proposta de Diewald (2002), como uma passagem por estágios. Os estágios são, pois, ordenados cronologicamente e associados a um contexto particular (DIEWALD, 2002).

Tendo em consideração que o contexto de base é o chamado contexto típico, da microconstrução no seu uso mais concreto, é pertinente mencionar novamente os vários estágios de mudança, parafraseando a descrição de Arena (2015):

- Contexto atípico: são evidentes as pré-condições de gramaticalização e presença de implicaturas conversacionais. Há uma expansão dos contextos nos quais a unidade construcional ainda não havia sido usada.

- Contexto crítico: a construção resulta mais marcada e caracteriza-se por múltiplas situações de ambiguidade estrutural e semântica, levando, por isso, a várias possibilidades de interpretação, entre elas o novo significado gramatical.

- Contexto de isolamento: é a consolidação do processo de gramaticalização. Nesta fase, o novo significado gramatical é isolado como um significado separado do significado básico, mais lexical. Essa separação dos dois significados é alcançada pelo desenvolvimento de contextos de isolamento para ambas as leituras, lexical e gramatical, ou seja, de contextos linguísticos específicos que favorecem uma leitura excluindo a outra. O novo significado gramatical não depende mais de implicatura conversacional, uma vez que o elemento linguístico em gramaticalização se tornou verdadeiramente polissêmico.

A tese de Arena (2015) foi indicativa do ponto de vista da diversificação dos contextos iniciais. A autora cita Traugott (2008) e a importância da determinação dos diversos contextos iniciais em um caso particular de gramaticalização, mais alerta que que efetivamente se deve concentrar em apenas um tipo específico do processo de mudança. Isso parece particularmente útil uma vez que encontramos dois contextos iniciais para a microconstrução no corpus em análise.

O primeiro contexto ou contexto típico, tal como em português, é un bel giorno no seu sentido descritivo e mais ligado à expressão do conteúdo:

(4) Qualche giorno più tardi, lui le telefonò dall'Olanda e le disse: "Oggi è un bel giorno". (http://room67.blogspot.com/2010/12/ corpus Paisà) 
(Alguns dias depois, ele a chamou da Holanda e disse: "Hoje é [um belo dia]". Tradução nossa)

Como esse uso (típico, clássico) se revelou muito reduzido no corpus DiaCORIS, nos perguntamos quais poderiam ser outras opções semelhantes de uso típico em italiano. A primeira opção encontrada foi a sua forma no feminino una bella giornata.

(5) Ma il mio sconforto non nasce per quelle nuvole, anzi, si fa strada proprio nel mezzo di una bella giornata, contro lo splendore del sole. (I Bei Momenti, Enzo Siciliano, 1998, corpus DiaCoris)

(Mas o meu desespero não nasce para aquelas nuvens, pelo contrário, ele faz o seu caminho bem no meio de um belo dia, contra o esplendor do sol. - Tradução nossa)

Pesquisando-se no corpus Paisà foram encontradas 56 ocorrências de una bella giornata com sentido descritivo e, portanto, típico. No corpus escrito DiaCORIS, foram verificadas 31 ocorrências, das quais 3 delas sugerem uma leitura de uso atípico, como é visível no exemplo que segue:

(6) Non obbedì al consiglio di qualche amico che gli suggerì di mandare la fotografia dell'assegno ad Antonio Baldini, che, pure essendo il più pacioso degli uomini, gli aveva avvelenata una bella giornata del 1922 - quando il sole della fama dell'autore di Mimì Bluette pareva non dovesse mai spegnersi. (Guido Da Verona, Orio Vergani, Il Nuovo Corriere Della Sera, 1949, corpus DiaCoris)

(Ele não obedeceu aos conselhos de alguns amigos que sugeriram enviar a fotografia do cheque a Antonio Baldini, que, mesmo sendo o mais pacífico dos homens, o tinha envenenado um belo dia do 1922 - quando o sol da fama do autor de Mimì Bluette parecia nunca se apagar. - Tradução nossa)

A relação entre as duas construções é clara, uma vez que, também os resultados para o uso atípico de un bel giorno mostraram o mesmo padrão semântico de una bela giornata nesse mesmo contexto:

(7) Nei giorni seguenti capitò relativamente spesso di trovare la zia Maglorie priva di sensi vittima dell'alcol, e un bel giorno, sotto Natale, la trovarono per terra a faccia sulla neve e morta. (Il Barilotto, Guy De Maupassant, 1884, corpus Paisà)

(Nos dias seguintes aconteceu com relativa frequência encontrar a tia Maglorie inconsciente vítima do álcool, e um belo dia, durante o Natal, eles a encontraram caída com o rosto na neve e morta. - Tradução nossa) 
É evidente que essa ancoragem no tempo cronológico mostra uma dessemantização em relação ao uso típico, uma vez que ocorre em ambiente de uma narração e é preterido o sentido descritivo da construção.

Também em italiano, e como indicou a Silva (2017), no contexto de uso atípico, un bel giorno tem o mesmo valor e sentido de um dia qualquer, um dia $X$, mas que já traz também informações a respeito da progressão narrativa.

Diacronicamente, é possível ver como os usos inovadores da construção já eram implementados no sistema do italiano por volta do final do século XIX, como demonstra este ótimo exemplo, no qual a construção mais tipicamente conhecida aparece seguida por um esclarecimento temporal:

(8) È pericoloso tenersi in casa tutto questo denaro disse d'un tratto. Perché? Perché si potrebbe sapere, sospettare e un bel giorno od una bella notte venirci a sgozzare in letto per derubarci. (Mastro Titta: Il Boia di Roma - Memorie di un carnefice scritte da lui stesso, autore sconosciuto, 1891, corpus DiaCoris)

(É perigoso manter todo este dinheiro em casa, disse ele de repente. Porquê? Porque você pode saber, suspeitar, e um belo dia ou uma bela noite vir e cortar nossas gargantas na cama para nos roubar. - Tradução nossa)

O exemplo é único nos corpora em italiano, precisamente porque nenhum outro caso foi encontrado, e, ainda hoje, na fala ou na escrita, um falante nativo italiano dificilmente o utilizaria em um contexto discursivo similar. O uso esperado seria una bella giornata. Este caso, portanto, é uma indicação de como uma (micro)construção pode evoluir principalmente a partir de licenças estilísticas inovadoras, confirmando a transição da construção para um papel de operador narrativo com ancoragem temporal.

Na parte teórica deste artigo já mencionamos que, no contexto crítico, a construção deve ser considerada um chunk, uma unidade formal [um bel giorno], um conjunto estrutural indissolúvel com sentido único. Este sentido é abstrato: o operador ajuda a organizar a narrativa e permanece a indicação da qualidade temporal na sequência dos eventos narrados. Assim, [un bel giorno], tal como [um belo dia], introduz o clímax da narrativa e a culminância de uma série de acontecimentos:

(9) $\mathrm{Ci}$ prova e ci riprova, finché [un bel giorno] con un treno speciale carica su diecimila supporters ed entra senza colpo ferire nella città. (http://italy.indymedia.org/news/2005/10/888122.php, corpus Paisà)

(Ele tenta e tenta novamente, até [um belo dia] entrar na cidade com um trem especial carregado com dez mil apoiadores e sem lutar. - Tradução nossa) 
Foram analisados então os três contextos de produtividade, conforme proposto por Diewald (2002), tendo sempre como referência os parâmetros de analise utilizados no trabalho de Silva (2017), com algumas pequenas alterações com fins de aperfeiçoamento. Os dados são do corpus Paisà. Os parâmetros de análise envolvem: posição na oração com respeito ao verbo, tipologia de sequência textual (narrativa, argumentativa ou descritiva), atuação sintática do construto e o valor semântico de un bel giorno em cada contexto de uso.

A análise quantitativa indicou que, também em italiano, o construto resulta preferencialmente posposto ao verbo, como em Oggi è un bel giorno. Os resultados para os dois parâmetros seguintes são diferentes do que foi verificado para o português. $\mathrm{Na}$ verdade, eles mostram resultados quantitativos opostos. Em italiano, de fato, neste primeiro contexto, a sequência textual em que encontramos a construção é principalmente descritiva, enquanto em português se encontra principalmente em sequências narrativas. O papel na organização sintática nas duas línguas também é oposto. Em italiano, no contexto típico, o construto é mais usado nas funções tipicamente exercidas pelo sintagma nominal (sujeito ou complemento); em português, por um sintagma adverbial (geralmente como único argumento de verbos apresentacionais). Quanto ao valor semântico, confirmamos o sentido lexical e concreto, com referência física e ancoragem do conteúdo no tempo e no espaço.

Vejam-se agora os resultados para o contexto atípico. Já como explicou Silva (2017), nesse contexto o novo significado pode ser gramaticalizado e surgir como uma implicatura conversacional, por isso dá-se a polissemia. Precisamente por essa razão, foi bem complicado individuar no corpus as ocorrências do uso atípico e, para exemplificar o trabalho empreendido, também escolhemos adotar como parâmetro distintivo a paráfrase do construto por um dia qualquer. Com referência ao parâmetro posição na oração, o que surgiu foi mais uma vez uma situação oposta àquela da língua portuguesa, com uma maioria de ocorrências com posição pré-verbal (36). Quanto à sequência textual, os resultados são bem símiles. Também em italiano o construto é mais utilizado em textos do discurso narrativo, nos quais representa uma ancoragem no tempo cronológico e opera na progressão narratológica. Podese assinalar também a presença de marcadores temporais, como anos ou festividades (un bel giorno agli inizi dell'87 ou un bel giorno, intorno a Natale).

Ao contrário do que se verifica em português, esse uso não aparece no italiano com muita frequência conjuntamente a verbos apresentacionais, que são mais frequentes junto ao contexto típico, por exemplo. Sintaticamente, un bel giorno resulta sempre como adjunto adverbial, enquanto que, semanticamente, o construto é abstratizado. Tal como em português, 
às vezes un bel giorno atípico é ligado ao tempo concreto e outras ao tempo vago da narratologia do texto.

Quanto aos resultados do contexto crítico, que também em italiano resultou o mais frequente, é possível traçar uma certa semelhança com os resultados observados no PB. Enquanto para o português ocorre inversão quantitativa quanto ao parâmetro posição, em italiano, confirmamos, mais uma vez, uma tendência de o construto aparecer majoritariamente antes do verbo e mesmo antes da sequência narrativa que introduz.

Confirmamos também a coocorrência de expressões de realce, como, finché, per poi e fino a quando e de conjunções adversativas no ambiente anterior à micro-construção un bel giorno, que, na escrita, ocorre quase sempre entre vírgulas. Essas particularidades ajudam na sinalização de que a história narrada está por chegar a um ponto de criticidade ou/e que algo novo, inesperado e relevante acontecerá (um clímax). O construto tem função sintática de operador textual, atuando estritamente na construção dos sentidos no nível das relações entre orações (entre os eventos) e não propriamente no nível da oração básica, da relação com o predicado.

Quanto ao parâmetro semântico, salientamos o fato de un bel giorno se tornar um verdadeiro chunk neste último contexto de mudança. Ao constituir-se operador textual um bel giorno forma um conjunto estrutural inseparável, diferente do uso em contexto típico, no qual se distinguem um adjetivo bel e um substantivo giorno. É verdade também que o construto perdeu seu valor de indicativo de beleza e introduz situações de clímax e contra expectativa em geral.

Confirmamos, também em italiano, a possibilidade de parafrasear o construto por all'improvviso (de repente, em italiano); o que indica a proximidade de um evento inesperado na narrativa exposta. Isso pode ser confirmado por quanto segue:

(11) La madre sta al gioco del figlio, finché però [un bel giorno] questi sparisce nel nulla. (https://www.cineblog.it/post/8450/the-orphanage-recensione-in-esclusiva-dalos-angeles, corpus Paisà)

(11 a) La madre sta al gioco del figlio, finché però [all'improvviso] questi sparisce nel nulla.

(A mãe brinca com o filho, até que um belo dia/de repente ele desaparece no ar. tradução nossa)

Ademais, destacamos a ausência de ocorrências relativas ao último estágio de mudança, segundo a proposta de Diewald (2002). No italiano, a microconstrução parece não 
ter chegado ao ponto de se isolar. Isso porque, além do ter adquirido um sentido mais abstrato (contexto crítico), un bel giorno ainda não presenta particularidades tais que a ponham em oposição com os outros contextos. Além do mais, em italiano também persiste a ligação ao tempo, e os contextos de uso não são estritamente especificados.

\section{Conclusões}

Neste artigo foram analisados os contextos de uso das microconstruções italianas do tipo un bel giorno que, à primeira vista, parecem muito semelhantes à sua equivalente em português. Por essa razão, a investigação foi realizada diametralmente à leitura e à análise da dissertação de mestrado de Michele Denise da Silva (2017). Esta pesquisa forneceu um exemplo excelente de análise dessa construção, o que possibilitou uma análise comparada português/italiano.

Tentamos identificar, sempre que possível, os pontos comuns e as diferenças na evolução e nos usos dessa microconstrução nas duas línguas em comparação. Consideramos primeiramente o corpus histórico DiaCORIS, devido à possibilidade de oferecer dados para a descrição dos contextos de preferência de uso entre os anos de 1861 e de 2001, e podemos ancorar a análise também considerando a influência de acontecimentos históricos, políticos e sociais na escolha de uso de um contexto ou outro, e, para evidenciar a trajetória de uso de un bel giorno frente a diferentes tipologias textuais.

O resultado envolveu a preferência geral pelos contextos atípico e crítico (com maioria de casos desse último tipo), a preferência de uso da microconstrução em períodos mais positivos politicamente e uma passagem gradual no uso da microconstrução de contextos literários e narrativos para contextos jornalísticos menos controlados e mais informais, orientados para a expressão da opinião.

Devido às limitações editoriais, escolhemos as teorias de Diewald (2002) para a análise dos contextos de mudança a partir dos resultados verificados no corpus Paisà que, como já foi dito, favorece resultados mais sistematizados e oferece melhor possibilidade de seleção de dados, se consideramos o pouco registro histórico de dados da língua italiana. No geral, observa-se uma certa semelhança de uso e funcionalidade entre as microconstruções comparadas, cujos usos típicos são formalmente idênticos. Identificamos os mesmos contextos de uso (típico, atípico e crítico) que Silva (2017) identificou para o português.

Destacamos dos resultados que: a) no contexto típico, un bel giorno ocorre principalmente em sequências descritivas, enquanto em português se encontra principalmente em sequências narrativas; b) no contexto atípico, há, mais uma vez, uma situação oposta 
àquela da língua portuguesa, com uma maioria de ocorrências em posição pré-verbal. Diferentemente do que Silva (2017) verificou para o português, a coocorrência de marcadores temporais (de ano, festividades etc) é um fator de distinção desses contextos no italiano, bem como a ausência de verbos apresentacionais, e, c) no contexto critico, foram confirmadas as tendências construcionais também em italiano, ou seja, a preferência pela posição anteposta ao verbo e o uso em contextos narrativos. Verificamos também a concomitância de expressões de realce e de conjunções adversativas junto ao uso de contexto crítico. Neste último contexto de mudança, un bel giorno assume função de operador textual, confirmando também a tendência visível no PB.

Concluímos afirmando que a microconstrução mais abstrata em italiano parece ter tido uma evolução contextual e diacrônica muito mais estável do que a sua contraparte em português. A não composicionalidade é uma alteração importante no âmbito da forma também em italiano, mas podemos destacar o valor emocional no uso da construção, evidente nos resultados da análise do corpus histórico. Neste, os dados revelaram que, nos últimos três séculos, a escolha por un bel giorno sempre esteve correlacionada à condição social e moral daqueles que a usaram. $\mathrm{O}$ uso mais abstratizado indica discursivamente a aproximação de um clímax e também sugere, semanticamente, uma mudança inesperada no curso dos acontecimentos e ideias.

\section{Referências}

ARENA, A. B. Construcionalização do conector daí que em perspectiva funcional centrada no uso. 2015. 192 f. Tese (Doutorado em Estudos Linguísticos) - Faculdade de Letras, Universidade Federal Fluminense, Niterói, RJ, 2015.

CORPUS PAISÀ. In: https://www.corpusitaliano.it/it/index.html.

CORPUS DIACORIS. In: http://www.corpora.dslo.unibo.it/DiaCORIS/.

DIEWALD, G. A. model for relevant types of contexts in grammaticalization. In: WISCHER, I.; DIEWALD, G. (Eds.). New reflections on grammaticalization. Amsterdam \& Philadelphia: John Benjamins, 2000. p.103-120.

FILLMORE, C. The mechanisms of 'Construction Grammar'. Berkeley Linguistics Society, v. 14 , p. 35-55, 1988.

GOLDBERG, A. Constructions: a construction approach to argument structure. Chicago: The University of Chicago Press, 1995.

GOLDBERG, A. Constructions at work: the nature of generalization in language. Oxford: Oxford University Press, 2006. 
JUSTINO, A. R. Construções comparativo-intensificadoras de valor absoluto - estudo do esquema X que só. 2018. 147 f. Tese (doutorado em Estudos Linguísticos) - Faculdade de Letras, Universidade Federal de Goiás, Goiânia, 2018.

MASINI, F. La grammatica delle costruzioni. Roma: Carocci, 2016.

PAREDES SILVA, V. L. Gêneros e tipos de texto: aproximações e distinções. Diacrítica, Braga, v. 24/1, p. 471-489, 2010.

PAREDES SILVA, V. L. Forma e função nos gêneros de discurso. ALFA, São Paulo, v. 41, p. 79-98, 1997.

SILVA M. D. Um estudo de um belo dia na perspectiva da gramática de construções. 2017. 132 f. Dissertação (Mestrado em Estudos Linguísticos) - Faculdade de Letras, Universidade Federal de Goiás, Goiânia, 2017.

SILVA, M. D; CASSEB-GALVÃO, V. C. Um belo dia resolvi mudar: uma análise dos usos da microconstrução um belo dia no português brasileiro. Laborhistórico, Rio de Janeiro, v. 5, p. 70-95, 2019.

SILVA, M. D. Um belo dia e seus contextos de gramaticalização. Polifonia, Cuiabá, v. 25, p. 273-296, 2018.

TRAUGOTT, E. C.; TROUSDALE, G. Constructionalization and Constructional Changes. Oxford: Oxford University Press, 2013.

\section{Sobre as autoras}

Vânia Cristina Casseb Galvão (Orcid iD http://orcid.org/0000-0001-6952-6623) Doutora em Linguística e Língua Portuguesa pela Universidade Estadual Paulista Júlio de Mesquita Filho (UNESP); mestra em Linguística pela Universidade Estadual de Campinas (UNICAMP). É professora do Departamento de Estudos Linguísticos e Literários da Faculdade de Letras e do Programa de Pós-Graduação em Letras e Linguística da Universidade Federal de Goiás (UFG); professora do Programa de PósGraduação em Linguística, Letras e Interculturalidade da Universidade Estadual de Goiás (UEG); e professora visitante na Università del Salento (Unisalento, Itália). Bolsista de Produtividade em Pesquisa do CNPq; pesquisadora contemplada com o auxílio do European Research Council (ERC) e do Brazilian National Council of State Funding Agencies to provide research in Ca Foscari University - Italy.

Carlotta Boellis (Orcid iD: http://orcid.org/0000-0001-6515-0489)

Mestranda em Tradução e Interpretação na Università del Salento (Unisalento, Itália); graduada em Mediação Linguística.

Recebido em junho de 2020.

Aprovado em setembro de 2020. 